\title{
OS NOVOS DESAFIOS DA EMPRESA DO FUTURO
}

\author{
José Ernesto Lima Gonçalves \\ Professor do Departamento de Administração Geral \\ e Recursos Humanos da EAESP/FGV.
}

RESUMO: O futuro pertence às empresas que conseguem explorar o potencial da centralização nos seus processos. A reengenharia e outras iniciativas destinadas a dar forma aos negócios e às organizações já transformaram o processo de trabalho; agora é necessário transformar as pessoas que trabalham nelas para conseguirem um conjunto capaz de desempenho superior. Geralmente a responsabilidade pelos assuntos relacionados aos recursos humanos nas empresas tem sido atribuída à área de RH. E é exatamente essa área que precisa enfrentar uma das mais difíceis partes do desafio na modernização das empresas. Parece que as armas convencionais e toda a experiência reunida pelo pessoal de recursos humanos não serão suficientes para resolver a questão. Este artigo sugere que será necessário romper com o passado, deixar de lado alguns conceitos e experiências tradicionais e criar novidades e soluções criativas para dotar as empresas do futuro dos recursos humanos de que elas irão precisar.

ABSTRACT: The future will belong to companies that can fully explore process centering. Reengineering and other initiatives bound to give new shape to organisations have already transformed the work to be done in companies. Now it is time to transform people that work in them, as to have teams capable of superior performance. In general, the subjects related to human resources are the responsability of the HR function. This is the very part of the company that needs to face the most difficult part of the modernization challenge. It seems, however, that the conventional weapons and accumulated experience of HR people may not be enough to settle the question. The article suggests that it will be necessary to break up the past, to leave some old concepts and experiences behind and to propose new creative solutions to give companies of the future the human resources they will need.

PALAVRAS-CHAVE: recursos humanos, desafios, modernização, futuro, organizações.

KEY WORDS: human resources, challenges, modernization, future, organisations. 
A organização orientada para processos ${ }^{1}$ está surgindo como a forma organizacional dominante para o século XXI. ${ }^{2}$ As organizações somente poderão obter $\mathrm{o}$ alinhamento $\mathrm{e} o$ desempenho necessários num ambiente de competição global e mudança permanente se conseguirem se focar nos seus processos. ${ }^{3} \mathrm{O}$ futuro vai pertencer às empresas que consigam explorar o potencial da centralização nos seus processos.

A reengenharia e outras iniciativas destinadas a dar nova forma aos negócios ${ }^{4} \mathrm{e}$ às organizações já transformaram o trabalho realizado nas empresas. Agora é necessário transformar as pessoas que trabalham nelas, de forma a conseguir um conjunto capaz de desempenho superior.

Geralmente a responsabilidade pelos assuntos humanos nas empresas tem sido atribuída à área de RH. ${ }^{5}$ É lá que vamos encontrar os setores especializados em gestão de pessoal, recrutamento e seleção, treinamento e desenvolvimento, benefícios, avaliação de desempenho, serviço social e planejamento de pessoal. E é exatamente essa área que precisa enfrentar um dos mais difíceis desafios na modernização das empresas. Os profissionais da área estão procurando mapear esse desafio para que possam responder adequadamente às demandas impostas pela nova situação.

Parece, no entanto, que as armas convencionais e toda a experiência reunida pelo pessoal de recursos humanos não serão suficientes para resolver a questão. $O$ texto que se segue sugere a necessidade de romper com o passado, deixar de lado algumas experiências tradicionais $\mathrm{e}$ criar novidades e soluções criativas para dotar as empresas do futuro dos recursos humanos de que elas irão precisar.

\section{A EMPRESA DO FUTURO}

A empresa do século XXI será organizada em torno de seus processos e centrará seus esforços em seus clientes. Ela será ágil e enxuta, seus jobs $s^{6}$ exigirão conhecimento do negócio, autonomia, responsabilidade e a habilidade na tomada de decisões. Nela, não haverá lugar para os empregados tradicionais, aqueles que as empresas prepararam durante tanto tempo e que hoje tripulam as nossas organizações.

Os modelos antigos de empresa, tanto do ponto de vista da estrutura organizacional, como da gestão das pessoas e do negócio não funcionam mais. ${ }^{7}$ As organizações tradicionais foram projetadas com base em pressupostos antigos, ${ }^{8}$ como a constância e regularidade do ambiente externo - que permitia à empresa isolar-se dentro de suas fronteiras -, a versatilidade da empresa - que permitia que ela produzisse tudo o que pudesse a custos inferiores aos de um fornecedor externo - a eficiência decorrente da especialização e a conseqüente estruturação em unidades especializadas estanques, além da prescrição detalhada dos procedimentos e metas pessoais, de modo a superar a limitação de conhecimentos e de capacidade dos empregados.

As organizações dos últimos cinqüenta ou sessenta anos foram desenhadas a partir de princípios organizacionais como aqueles apresentados no quadro 1 e que não são mais válidos. ${ }^{9}$ Hierarquia, especialização por funções, unidade de comando, pagamento proporcional à posição hierárquica, períodos operacionais anuais e amplitude de controle eram as diretrizes gerais básicas que orientaram o desenho das organizações desde que foram definidas na década de 30 .

\section{Quadro 1}

OS PRINCÍPIOS TRADICIONAIS DO
DESENHO ORGANIZACIONAL ${ }^{10}$
\begin{tabular}{l}
\hline Princípios tradicionais \\
\hline Hierarquia \\
\hline Divisão do trabalho \\
\hline Amplitude de controle \\
\hline Disciplina \\
\hline Unidade de comando \\
\hline Especialização funcional \\
\hline Cadeia de comando \\
\hline Valor de acordo com posição hierárquica \\
\hline Comunicação formal em papel \\
\hline
\end{tabular}

Esses princípios levaram à adequação das empresas para as décadas seguintes: bem estruturadas, claramente organizadas, altamente eficientes na produção de determinados bens materiais em quantidades cada vez maiores e bastante estáveis em termos de resultados. No entanto, esse modelo de empresa certamente não é mais adequado ao atendimento das características mutantes do mundo contemporâneo.
1. No original process-oriented organisation, no sentido de uma organizaçăo estruturada em função de seus processos fundamentais.

2. HAMMER, Michael. Towards the twenty-first century enterprise (folheto) Boston: Hammer \& Co., 1996.

3. No sentido aqui empregado, "processo" é o conjunto de atividades realizadas numa sequêencia lógica e que gera um produto que tem valor para um determinado grupo de clientes.

4. SHAPIRO, Eileen. Fad surfing in the boardroom. Addison-Wesley, 1995.

5. A sigla RH será utilizada neste texto para referência genérica às diversas formas da área responsável pelos recursos humanos nas empresas.

6. "Job" é uma palavra riquissima, podendo significar cargo, tarefa, emprego ou papel, dependendo do contexto. Neste parágrafo, preferimos utilizá-la em inglês.

7. GONÇALVES, José Ernesto Lima. A necessidade de reinventar as empresas. EAESP/FGV, 1996.

8. DREYFUSS, Cássio. A organização do ano 2000: a reengenharia, a tecnologia e - resultado dos negócios. In: GONÇALVES, José Ernesto Lima (ed.).

Reengenharia das empresas: passando a limoo. São Paulo: Atlas, 1995.

9. NOLAN, Richard e CROSON, David. Creative destruction. s.l., Harvard Business School Press, 1996.

10. Adaptado de Nolan \& Croson. Op. cit. 
Além disto, esses princípios baseavam-se nas características específicas da tecnologia gerencial da época e nos valores e estilos gerenciais então vigentes. Não apenas a tecnologia moderna facilitou a coleta, a organização, a consolidação, a transmissão, a armazenagem e a análise das informações operacionais das empresas, mas a maneira de gerenciar os recursos, em geral, e as pessoas, em particular, mudou fundamentalmente. Com isso, as organizações modernas passam a ser projetadas com base em novos princípios, como os apresentados no quadro 2 , mais adequados à tecnologia e ao estilo gerencial contemporâneos. Entre esses novos princípios, temos o da alocação de recursos em tempo real, o da comunicação ponto a ponto, o da organização do trabalho em times e projetos, o da avaliação de desempenho por resultados e o das fronteiras orgânicas.

\section{Quadro 2} DESENHO ORGANIZACIONAL

Princípios contemporâneos

Alocação dinâmica de recursos

Comunicação ponto a ponto

Trabalho realizado em times

Criação de valor

Monitoração de resultados

Trabalho organizado em projetos

Fronteiras orgânicas

Oportunidade

Coordenação

A centralização das empresas em seus processos levará a desenhos organizacionais muito diferentes dos que conhecemos. O primeiro estágio, não apenas previsível, mas que já está sendo adotado em muitas empresas, é o de redistribuir os recursos humanos e técnicos das 11. Adaptado de Nolan \& Croson. Op. cit. 12. As conversas do Prof. Moyses Sznifer, da EAESP/FGV com o autor vão exatamente nesta linha.

13. HANDY, Charles. The age of unreason. S.l., Harvard Business School Press, 1989.

14. Esta preocupação tem estado presente nas perguntas dos participantes dos seminários de Gestão da Transformação Organizacional realizados pela EAESP/FGV em São Paulo. As parcerias e as redes de empresas estão surgindo como um segundo estágio desse movimento de reforma conceitual, sendo que nem todos os recursos essenciais para a operação da empresa encontram-se dentro dela e nem pertencem a ela.

É de se prever, no entanto, que essa renovação prosseguirá por caminhos ainda mais radicais. ${ }^{12} \mathrm{O}$ fim das relações duráveis entre em-

\section{OS MODERNOS PRINCIPIOS DO}

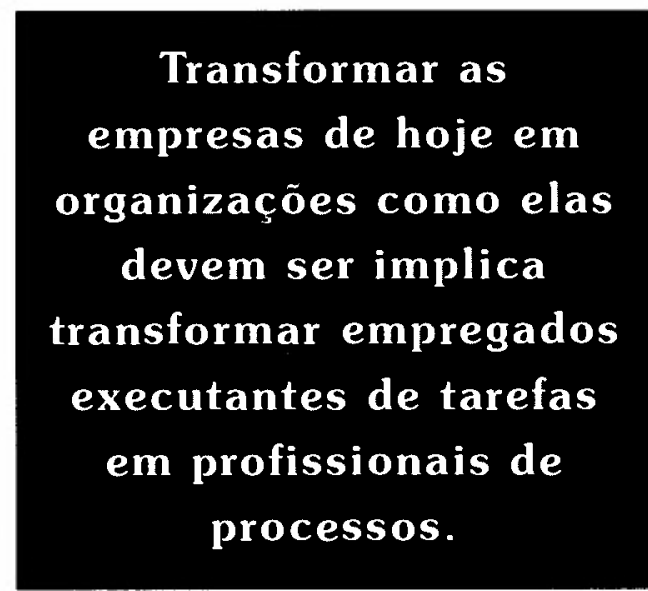

presa e empregados, o realinhamento constante dos recursos para a adaptação aos desafios internos e externos e a redefinição do modelo de distribuição de responsabilidades e poderes nas organizações levarão a modelos organizacionais que podemos apenas imaginar. ${ }^{13}$

\section{OS NOVOS DESAFIOS}

As empresas modernas já estão procurando funcionar com características mais adequadas aos novos tempos. Geralmente são empresas com quadro de pessoal enxuto, número muito menor de níveis hierárquicos, novas formas de estrutura organizacional, inclusive com uso o intenso da terceirização e desenho organizacional baseado nos processos de negócio, o que exige profunda redistribuição das tarefas dentro das empresas.

A análise dos diversos fatores de mudança organizacional, tanto internos como externos, tem gerado apreensão e curiosidade por parte dos executivos das empresas modernas. ${ }^{14}$ Muitas perguntas surgem a respeito da evolução do papel das funções organizacionais nas empresas do futuro e sobre o que esperar dos profissionais dessas funções básicas. Em particular, as perguntas demonstram uma preocupação concentrada no futuro da área de recursos humanos.

À medida que as empresas se centram em seus processos, as demandas colocadas sobre o pessoal de linha de frente mudam drasticamente. $O$ pessoal deve ir de um ambiente de foco estreito e supervisão cerrada para um ambiente que enfatiza os clientes, o trabalho em times e a iniciativa dos empregados. Por outro lado, se os "gerentes" ou coordenadores são elementos fundamentais na gestão dos recur-

$R A E \cdot$ v. $37 \cdot$ ก. $3 \cdot$ Jul./Set. 1997 
sos humanos da empresa, eles devem estar devidamente preparados para essa função.

Do ponto de vista dos recursos humanos, o grande desafio a ser enfrentado é desenvolver empregados de todos os níveis para a empresa baseada em processos. Em princípio, para promover a transformação das empresas como hoje as conhecemos, dentro de organizações, em como elas devem ser é necessário:

- transformar empregados de tarefas em profissionais de processo;

- repensar os papéis dos administradores ${ }^{15}$ e dos empregados nas empresas estruturadas por processos ;

- reinventar os sistemas de gestão de recursos humanos, desde o treinamento até os esquemas de reconhecimento dos esforços;
- fazer com que o aprendizado seja parte do dia-a-dia dos negócios da empresa;

- moldar uma nova cultura que dê suporte à nova maneira de trabalhar.

Além disso, também há a necessidade de estruturar empresas com pouca gente, quadros enxutos e muito ajustados, definição difusa de atribuições, polivalência, poucos níveis hierárquicos, novas formas de estrutura organizacional, redistribuição de tarefas, estruturação dinâmica.

No quadro 3, são apresentados alguns exemplos dos desafios trazidos às empresas pelas novas características operacionais que as organizações devem apresentar para o seu ajuste às condições previstas para a virada do século.

\section{Quadro 3}

\section{CARACTERISTICAS DAS NOVAS ORGANIZAÇÕES}

\begin{tabular}{|c|c|}
\hline Características & Desafios \\
\hline $\begin{array}{l}\text { Empresas com pouca gente; } \\
\text { quadro enxuto }\end{array}$ & $\begin{array}{l}\text { - proporcionar treinamento nas novas funções } \\
\text { - treinar empregados polivalentes e grupos } \\
\text { multifuncionais } \\
\text { - definição difusa das atribuições } \\
\text { - desenvolver formas de treinamento sem afastamento } \\
\text { - desenvolvimento da polivalência }\end{array}$ \\
\hline $\begin{array}{l}\text { Empresas com menor número } \\
\text { de níveis hierárquicos }\end{array}$ & $\begin{array}{l}\text { - renovar idéia do plano de carreira } \\
\text { - disseminar novas ferramentas de comunicação } \\
\text { - criar novos esquemas de reconhecimento/remuneração } \\
\text { - prover melhor preparo/visão dos líderes }\end{array}$ \\
\hline $\begin{array}{l}\text { Quadro de pessoal mais } \\
\text { ajustado }\end{array}$ & $\begin{array}{l}\text { - dar apoio a quem fica depois das dispensas } \\
\text { - desenvolver técnicas de como dispensar } \\
\text { - prover apoio para quem sai }\end{array}$ \\
\hline $\begin{array}{l}\text { Novas estruturas } \\
\text { organizacionais; uso intenso } \\
\text { de terceirização }\end{array}$ & $\begin{array}{l}\text { - divulgação e discussão dessas idéias } \\
\text { - preservação do clima e cultura }\end{array}$ \\
\hline Estruturação dinâmica & $\begin{array}{l}\text { - desenvolvimento da polivalência } \\
\text { - novos mecanismos de ambientação } \\
\text { - competência em gestão da mudança } \\
\text { - desenvolvimento eficaz de lideranças }\end{array}$ \\
\hline $\begin{array}{l}\text { Organização por } \\
\text { processos: redistribuição } \\
\text { de tarefas e recolocação } \\
\text { de pessoal }\end{array}$ & $\begin{array}{l}\text { - realizar estudos e operação de benefícios } \\
\text { - ajudar o responsável pela redistribuição } \\
\text { - desenvolver programas de retreinamento } \\
\text { - facilitar a recomposição dos grupos } \\
\text { - manter banco de dados de oportunidades }\end{array}$ \\
\hline
\end{tabular}

15. A própria palavra "administrador" deverá ser redefinida para englobar tanto a função gerencial como 0 espírito empreendedor. Não temos, em português, uma palavra abrangente como "manager", que abrange todas as posições que gerenciam as pessoas e tarefas da sua área de responsabilidade. 
As novas formas de organização que estão surgindo também exigem o desenvolvimento de novos modelos de administração. Tem crescido muito a importância da administração de pessoal, incluindo elementos complicadores como a reorganização das linhas de poder e a recomposição dos quadros. Os projetos de redefinição estratégica das empresas têm exigido a implementação de mudanças organizacionais em larga escala. Essas características das novas organizações trazem novos desafios para a área de recursos humanos, como mostra o quadro 4 .

Nota-se que grande parte desses desafios está ligada diretamente às habilidades e responsabilidades do que se convencionou chamar de "área de recursos humanos" das empresas. No entanto, as "áreas de recursos humanos" não estão preparadas nem estruturadas para enfrentar esses desafios com sucesso. Afinal, foram concebidas e estruturadas para resolver outro tipo de desafios.

As características das novas formas de realizar o trabalho também oferecem novos desafios à área de recursos humanos, como mostra o quadro 5. De maneira geral, todos os responsáveis pela gestão das empresas precisarão redesenhar os sistemas e redefinir os critérios com os quais as empresas são administradas e caberá aos especialistas em recursos humanos dar o apoio necessário para esse esforço de reestruturação.

O trabalho nas empresas modernas envolve produzir em organizações virtuais, pressupondo o emprego das novas tecnologias, a realização de trabalho em ambiente de rede e estabelece que o modo normal de produção é a execução de tarefas em grupos e em células de pessoas.

Em particular, será importante investir boa dose de esforço e tempo no projeto do trabalho, ${ }^{16}$ de maneira a explorar novas formas de realizar as funções características da organização e a aperfeiçoar os esquemas de trabalho que envolvem diversas pessoas. A falta de pessoas especializadas no projeto do trabalho possivelmente sugere que parte dessa responsabilidade deva passar para o pessoal de $\mathrm{RH},{ }^{17}$ que precisa ser preparado para desempenhar essa função de forma adequada.

Ao contrário do que ocorreu durante as décadas do período de fartura, ${ }^{18}$ a empresa mo-

\section{Quadro 4}

16. Projeto do trabalho é a definição básica das regras e procedimentos gerais a serem observados na execucão das tarefas rotineiras nas empresas. Pode ser realizado em diversos níveis de detalhe, em funçāo das necessidades específicas e dos objetivos do estudo.

17. GONÇALVES, José Ernesto Lima. Um novo $0 \& M$ para recuperar o tempo perdido. RAE Light São Paulo: Fundaçāo Getúlio Vargas, v. 2, n. 3, mai//un 1995.

18. A economia americana viveu quase três décadas ("The Golden Years") de imensa fartura e grande desenvolvimento logo após a Segunda Guerra Mundial, enquanto as economias da Europa e Japão se reconstruíam. Guardadas as proporções e devido ao modelo americano de gestão que adotam, os comentários sāo válidos também para as empresas instaladas no Brasil.

\section{OS DESAFIOS DA GESTÃO DAS NOVAS ORGANIZAÇŌES PARA O RH}

\begin{tabular}{|l|l|}
\hline Características & Desafios \\
\hline Enfase na administração das & - redefinir o contrato social entre a empresa e os \\
pessoas & $\begin{array}{l}\text { - moldar novo sistema de valores que motivem e } \\
\text { orientem } \\
\text { - melhorar a qualificação dos gerentes para desafios } \\
\text { - desenvolver mecanismos de gestão mais modernos } \\
\text { - desenvolver novos padrões no gerenciamento de } \\
\text { carreiras }\end{array}$ \\
\hline Implementação de mudanças & - mudança como projeto de recursos humanos \\
em larga escala & - preparar a massa trabalhadora para a nova empresa \\
& - monitorar o clima organizacional \\
& - desenvolver visão de médio e longo prazos \\
& - definir o papel de RH na administração da mudança \\
\hline Reorganização das linhas de & - propor novas estruturas organizacionais \\
\hline poder & - garantir apoio aos grupos de mudança \\
\hline Recomposição dos quadros & - prover orientação a chefes e supervisores \\
& - desenvolver novos padrões de seleção de pessoal \\
& - garantir apoio na seleção de pessoal \\
\hline
\end{tabular}


Quadro 5

\begin{tabular}{l} 
DESAFIOS DAS NOVAS FORMAS DE TRABALHO PARA O RH \\
\begin{tabular}{|l|l|}
\hline Requisitos & Desafios \\
\hline $\begin{array}{l}\text { Trabalho em organizações } \\
\text { virtuais }\end{array}$ & - desenvolver treinamento remoto \\
& - apoio na criação de novos mecanismos gerenciais \\
& - preservação do clima e cultura \\
& - criação de novos esquemas de reconhecimento/ \\
& remuneração \\
& - disseminação de novas ferramentas de comunicação \\
\hline Novos usos de & - promover a aproximação com a tecnologia \\
tecnologia e uso de & - pesquisar impactos da tecnologia e oportunidades \\
novas tecnologias & - orientar o desenho de novas funçães \\
& - explorar uso de ferramentas intelectuais (como a \\
criatividade)
\end{tabular} \\
\hline Trabalho em ambiente de \\
rede
\end{tabular}

derna deverá ser muito competente em todas as suas atividades, aperfeiçoando permanentemente suas características operacionais. A capacidade da empresa de aprender com sua experiência certamente será um fator de crescente importância para o desenvolvimento de seus mecanismos de aperfeiçoamento. A idéia é que as empresas saibam aprender com todas as experiências a que tiverem acesso, tornando-se o que se chama "learning organisation". Na prática, os programas de demissão voluntária estão demonstrando a fragilidade das organizações que temem perder as pessoas que detém o seu know-how, por não serem, em geral, organizações competentes para aprender. ${ }^{19}$

A internacionalização das empresas e a operação em tempo real trazem o desafio de lidar com a variedade e com a complexidade dos novos modelos de gestão. ${ }^{20}$ Introduzem variáveis diferentes, como a mobilidade social de seu pessoal, a gestão de empresas internacio-

$R A E$ • v. 37 • n. 3 • Jul./Set. 1997 nais, regras que incentivam cada vez mais a integração do pessoal e a diversidade cultural no ambiente de trabalho. Provocam o rompimento com premissas fundamentais dos modelos anteriores: jornada de trabalho, fusos horários, ciclos mensais e anuais.

A internacionalização das empresas e a globalização de suas operações também têm trazido novos desafios para as áreas tributária, contábil e trabalhista das empresas modernas. Afinal, não faz sentido estruturar e gerir empresas internacionais através de práticas atreladas às regras trabalhistas locais, ou restringir a estratégia financeira de um grupo empresarial internacional à particular legislação tributária de um único país.

Algumas ferramentas básicas de administração de recursos humanos já não fazem sentido (até atrapalham), mas estão firmemente incorporadas à filosofia de gestão contemporânea e à expectativa das pessoas em geral: as
19. Este período, de 1996 a 1997, está sendo muito rico em programas governamentais de demissão voluntária e as diretrizes desses programas e as preocupaçōes de seus idealizadores, em termos de limitar o número de candidatos e de impedir que os ocupantes de determinados cargos se inscrevam tem exatamente este sentido.

20. RHINESMITH, Stephen. $A$ manager's guide to globalization. s.I., Irwin, 1996. 
21. SOLOMAN Charlene. Como lidar com a nova geração de administradores. São Paulo: Fundação Getúlio Vargas, RAE, v. 34, n. 2, mar./abr. 1994.

22. PEREIRA FILHO, João Lins e WOOD JR. Thomas. Remuneração estratégica. São Paulo: Fundação Getúlio Vargas, RAE Light, v. 2, n. 4, 1995

23. BERGAMINI, Cecilia Whitaker. Premiar não é a solução. São Paulo: Fundação Getúlio Vargas, RAE Light, v. 2, n. 1, 1995 e KOHN, Alfie. Porque os planos de incentivo não funcionam. São Paulo: Fundação Getúlio Vargas, $R A E$, v. $35, \mathrm{n}$. 6, nov./dez. 1995

24. BLAKSTAD, Michael. Promover é o único caminho? Management, v. 1, n. 1 , mar./abr. 1997.

25. HAMMER, Michael. Beyond reengineering. s.I., Harper Collins, 1996.

26. 0 assunto surge em conversas do autor com Cássio Dreyluss e nas obras de James Brian Quinn e Don Tapscott. Essa rede (network) de coordenação é a própria essência da estrutura organizacional em alguns tipos de empresa.

27. LIPNACK, Jessica. The age of the network. s.I., Omneo, 1994.

28. No original, o termo "entitlement" refere-se à atitude de quem acha que não precisa ganhar o que recebe, que crê que recebe pelo que é e não pelo que faz.

29. BARDWICK, Judith. Danger in the comfort zone. s.l., Amacon, 1995.

30. Também chamada de "quality of work life" noções de carreira e de progressão vertical, descrição de cargos, a periodicidade na progressão, a avaliação de desempenho individual etc. As profundas transformações que as empresas vêm sofrendo exigem novos esquemas de remuneração. ${ }^{21}$ Nas empresas caracterizadas por sistemas de trabalho diferenciados (células de produção, empregados multifuncionais e poucos níveis hierárquicos) não faz sentido recompensar a contribuição individual, ou mesmo a coletiva, com base apenas na descrição de atribuições e responsabilidades. ${ }^{22} \mathrm{Os}$ mecanismos de promoção e premiação freqüentemente adotados pelas empresas têm sido muito questionados, havendo pesquisas que levam à conclusão de que premiar não é a solução para a motivação do pessoal, ${ }^{23}$ nem promover é a melhor alternativa do ponto de vista da empresa. ${ }^{24}$

No início da década de 80 , estava na moda a automação de escritórios. Quando o uso de computadores passou a diminuir o tempo necessário para a realização das tarefas do escritório e o tempo dos empregados começou sobrar, os gerentes foram chamados a gerenciar. Foi necessário redistribuir tarefas para rebalancear a carga da equipe, acompanhar seu pessoal em novas atividades, buscar níveis adequados de capacitação para seu pessoal, repensar a dinâmica do trabalho de sua equipe. Mais recentemente, com as preocupações que levaram à reengenharia dos processos e à redefinição dos negócios das empresas, os gerentes estão sendo deslocados para a zona de contato com os clientes, o que muitas vezes implica em olhar para a parte mais baixa do organograma convencional. Alguns gerentes estiveram tanto tempo longe de qualquer tipo de trabalho substantivo, que perderam qualquer contato com ele e com a sua realidade. ${ }^{25}$

Basicamente, a estrutura das empresas do futuro terá dois grandes níveis de organização, com características bem diferentes: os processos operacionais a que já nos referimos e a rede de coordenação, ${ }^{26}$ tanto interna, quanto externa. Para que esse modelo funcione adequadamente, será necessário desenvolver nas pessoas a habilidade de trabalharem em rede. ${ }^{27}$

A complacência da administração que vigorou durante décadas após a Segunda Guerra levou as empresas a serem tolerantes com a mediocridade e permitiu que nelas se instalasse uma filosofia do "direito adquirido". ${ }^{28}$ As consequiências têm sido terríveis para as empresas americanas e para aquelas projetadas e administradas pelo modelo americano, como ocorre com as brasileiras: a perda da capacidade de competir, a acomodação e a falta de agilidade. Uma das maneiras eficazes de combater essa atitude tão profundamente enraizada nas empresas é por meio da criação de uma dose adequada de ansiedade, que arranque as pessoas da passividade. ${ }^{29}$ Não há como levar as pessoas da complacência à produtividade sem uma profunda mudança de mentalidade. A criação dessa dose de ansiedade e a conseqüente monitoração do nível de ansiedade são esforços que exigem muita competência e preparo em lidar com as pessoas.

Estamos procurando identificar os fatores externos e internos que levam a empresa a ter um desempenho superior. As empresas têm se dedicado ao tratamento das forças externas, desenvolvendo novos modelos de gestão estratégica e novas técnicas de análise organizacional. Entre os fatores internos, encontramos a qualidade de vida no trabalho ${ }^{30} \mathrm{e}$ a motivação do seu pessoal. Algumas forças internas provocam boa parte da pressão por mudanças: o nível médio de escolaridade cada vez melhor e preparo do pessoal, bem como a correspondente expectativa de participar das decisões, dos resultados e do futuro da organização.

\section{TRANSFORMANDO AS PESSOAS}

Transformar a força de trabalho passou a ser o maior desafio estratégico enfrentado pelas empresas que esperam ter sucesso no próximo século. E, como a transformação das pessoas dá-se através da educação, o desafio é principalmente de educação e reeducação de todos os níveis e grupos dentro das empresas.

Os processos modernos alavancam fortemente as competências individuais das pessoas que os executam. Durante muito tempo, as empresas não se preocuparam com a capacitação do seu pessoal, depois passaram a valorizar o treinamento do pessoal operacional, inclusive como recurso para a redução de erros e de custos de produção e, mais recentemente, têm passado a se preocupar com a capacitação do pessoal que gerencia os seus recursos e produz através desses mesmos recursos.

Por outro lado, a capacitação do pessoal geralmente se deu de maneira pontual, freqüen- 
temente fora do ambiente de trabalho e com pequena abrangência. $O$ que se exige hoje é a capacitação pelo aprendizado contínuo, incorporando a experiência e os novos conceitos às pessoas e ao know-how da empresa de maneira permanente.

Praticamente todos nós fomos aos poucos aprendendo e incorporando princípios e conhecimentos que não funcionam mais. Há trinta ou quarenta anos, as pessoas passariam a sua vida profissional aprendendo e utilizando um único conjunto de conhecimentos e técnicas e as novas técnicas seriam ensinadas para a geração seguinte. Atualmente o conjunto de técnicas e conceitos muda várias vezes de maneira completa ao longo de uma vida profissional. Como fazer para que as pessoas desaprendam as práticas passadas? Certamente, as técnicas convencionais, que agregavam conhecimentos novos aos antigos não são mais adequadas. Talvez precisemos de uma escola de "desaprendizado". 31

\section{É sintomático notar que}

a moderna bibliografia internacional sobre gestão, transformação organizacional e mudanças praticamente

não faça referência à área funcional de administração de recursos humanos.

Muitas empresas têm obtido resultados notáveis organizando-se em função de processos e projetos, agrupando seu pessoal em times e dando a eles autonomia sem precedentes. No entanto, trabalhar eficazmente em grupos não é intuitivo. Para terem sucesso em suas novas tarefas, os empregados precisarão de novos conhecimentos, novas habilidades e novos comportamentos, desde a compreensão de processos inteiros até a solução de problemas e a demonstração de iniciativa. Precisarão, também, aprender a trabalhar em grupos da maneira mais eficaz possível.
Por outro lado, os novos empregados não aceitam nem precisam das formas tradicionais de supervisão e gerência. ${ }^{32}$ Em vez disto, eles precisam de coaching ${ }^{33}$ e orientação, que, infelizmente, a maioria dos gerentes tradicionais não está preparada para prover. Assim, além de novos trabalhadores, deveremos preparar novos gerentes e administradores para desafios que eles ainda estão começando a enfrentar.

A transformação dos empregados não será automática, rápida, e nem mesmo fácil. Ela desafia um século de tradições e requer que a organização vá contra a corrente da nossa cultura contemporânea. Em princípio, a agenda de transformação das pessoas que tripularão as empresas do futuro inclui:

- como desenvolver e gerenciar o pessoal para os novos papéis que deverão assumir; - como utilizar novos modelos de avaliação de desempenho, remuneração e educação do pessoal;

- como criar uma organização em que cada pessoa esteja voltada à criação de valor para os clientes;

- como saber empregar técnicas para reformular a cultura, adequando-a ao novo mundo dos negócios.

Estamos assistindo à montagem de uma forma de "meritocracia", observada nas empresas que baseiam seu sucesso na atração, seleção e manutenção de quadros compostos quase que exclusivamente por pessoas brilhantes. Algumas pesquisas indicam que a inteligência é um dos melhores indicadores de sucesso numa ampla gama de cargos de todos os níveis em todos os tipos de organização. ${ }^{34}$ Os indivíduos brilhantes constituem um grupo particularmente desafiador para a realização das atividades que estamos mencionando aqui.

\section{UM NOVO RH OU NENHUM?}

Algumas empresas já estão eliminando suas áreas de recursos humanos, mais ou menos como fizeram com seus departamentos de O\&M em meados da década de 80 e com suas assessorias de planejamento estratégico no início dos anos $90 .{ }^{35}$ Provavelmente o modo de organização, o tipo de soluções propostas e a forma pela qual essas áreas funcionavam já não eram mais compatíveis com os desafios enfrentados pelas empresas. As empresas estão procurando maneiras radicalmente novas de resolver seus de-
31. A empresa do ano 2020. Management, vol. 1, n. 1, mar./abr. 1997

32. SOLOMAN, Charlene. Como lidar com a nova geração de administradores. São Paulo: Fundação Getúlio Vargas, $R A E, \mathrm{v}$ 34, n. 2, mar./abr. 1994.

33. A palavra "coaching" se refere à atuação do lider dos grupos, análoga à do treinador técnico de um time de futebol ("coach"); quando ele prepara os ogadores, define suas posições de jogo escolhe a estratégia de atuação e acompanha o resultado do jogo.

34. Microsoft big advantage - hiring only the supersmart. Fortune, November $25,1996$.

35. GONÇALVES, José Ernesto Lima. A necessidade de reinventar as empresas. EAESP/FGV, 1996 
36. ASTIZ, Ana. RH vira consultoria interna. Folha de São Paulo. 16 de outubro de 1994.

37. PEREZ, Luis. Integração de software aperfeiçoa RH. Folha de Săo Paulo. 6 de agosto de 1995

38. KATZENBACH, Douglas. The wisdom of teams. Cambridge: Harvard Business School Press, 1994.

39. MARIN, Denise Chrispim. Empresas inventam novos cargos. Folha de Săo Paulo. 16 de outubro de 1994 safios. Em algumas empresas, como a Elevadores Atlas, do grupo Villares, a antiga área de recursos humanos foi transformada em uma equipe de consultoria interna. ${ }^{36}$ Antigos analistas (de cargos e salários, de treinamento, de recrutamento e seleção) tendem a tornarem-se mais consultores do que técnicos, realizando estudos em relações humanas e dando suporte para os ocupantes de cargos gerenciais em programas de produtividade e reengenharia. Nas empresas modernas, a execução da maioria das tarefas que eram características da área de RH passou para as demais áreas da empresa, com orientação, suporte e treinamento da equipe de RH.

É sintomático notar que a moderna bibliografia internacional sobre gestão, transformação organizacional, mudanças e outros tópicos que se relacionam com profundas alterações na maneira de envolver, conduzir e orientar as pessoas praticamente não faça referência à área funcional de administração de recursos humanos. Aliás, esses trabalhos sempre apresentam essas funções como desafios da administração das empresas como um todo ou de certos papéis individuais bem identificados.

Provavelmente é necessário redefinir a missão da área de recursos humanos das empresas. Outra estratégia é eliminar a área de RH de uma vez. O paralelo com a situação da Informática e da Tecnologia de Informação é marcante: até uma determinada época, não existiam nas empresas áreas especializadas para tratar desses assuntos. Depois sugiram áreas que não apenas se especializaram, como também cresceram, sofisticaram-se e passaram a ter o monopólio dos assuntos ligados à informática dentro das empresas. Era como se as demais pessoas não tivessem nada a ver com a informática nem com os assuntos de recursos humanos. Mais recentemente, no entanto, a informática passou a ser ferramenta do dia-a-dia das pessoas e os assuntos de recursos humanos vão pelo mesmo caminho. Por analogia, a solução pode ser envolver todas as áreas da empresa no planejamento dos assuntos ligados com recursos humanos, capacitar o maior número possível de empregados para o uso das ferramentas específicas e manter um núcleo técnico muito pequeno para as tarefas técnicas altamente especializadas e para a consultoria interna. Não é mais possível aceitar monopólios e reservas de mercado desse tipo nas empresas que precisam se modernizar profundamente. Como já foi dito da tecno- logia de informação há uns cinco anos, o recurso humano é muito importante para ser deixado exclusivamente a cargo da área de $\mathrm{RH}$.

Apenas como exemplo, a utilização de sistemas informatizados inicialmente alterou as rotinas de trabalho da área: cadastro de pessoal, preparação de folha de pagamento, registro e controle de frequiência. Depois passou a ser utilizada para auxiliar a tomada de decisões: programação de férias e licenças, simulação de valores em negociações, planejamento de carreira etc. ${ }^{37}$ Mais recentemente, a utilização de sistemas integrados e de tecnologias mais avançadas tem permitido fazer análises sofisticadas de perfil psicológico de empregados, candidatos e concorrentes, análise de desempenho de chefias etc., o que muda a forma de trabalhar do pessoal que lida com seleção de pessoal, na chefia de grupos. Com tudo isso, a área de recursos humanos tem mudado, não apenas em termos de atribuições, mas também em termos de composição e organização interna.

À medida que as pessoas mudam, todos os sistemas da área de recursos humanos deverão ser repensados a partir do zero. As antigas práticas de recrutamento e avaliação, remuneração e desenvolvimento terão pouco valor nessa nova situação. As empresas precisam de sistemas que encorajem o aprendizado e a iniciativa, que facilitem o crescimento pessoal e motivem todos a centrar seus esforços no cliente.

Os sistemas administrativos das empresas deverão ser totalmente redesenhados para reforçar uma orientação na direção do aprendizado, com ênfase especial na mensuração do desempenho e na compensação dos empregados, com a visão de trabalho em times. ${ }^{38}$ Os sistemas de gestão do desempenho e de compensação devem dar suporte aos programas de mudança das empresas. É muito frequiente encontrar empresas em que os melhores esforços de modernização das formas de trabalho e da montagem de equipes de alto desempenho são sabotados por mecanismos antiquados de avaliação de desempenho individual ou por falta de uma política de desenvolvimento integrado dos recursos humanos. São muitas as empresas em que a modernização da área de recursos humanos limitou-se à substituição da palavra "empregado" pela palavra "colaborador" nos discursos internos.

Novos cargos vão sendo criados, cada vez mais distantes da descrição convencional. ${ }^{39}$ Não apenas surgem cargos com títulos inova-

RAE • v. 37 • n. 3 • Jul../Set. 1997 
dores, como líder de grupo, facilitador de processos, otimizador de desempenho etc., como as descrições desses cargos e de outros são cada vez mais abrangentes e pouco detalhadas.

Nesse contexto, não existe mais espaço para a área de RH convencional. As outras áreas das empresas estão se modernizando radicalmente, reavaliando sua atuação e suas técnicas. Até mesmo conceitos seculares estão sendo escrutinizados e abandonados, quando não mais conseguem se justificar. Não é possível, em âmbito de uma unidade da empresa ou da organização como um todo, continuar a chamar as pessoas de recursos e tratá-las como uma "commodity". O RH precisa urgentemente de alguma forma de reposicionamento, se não quiser seguir o caminho das áreas de O\&M. ${ }^{40}$

\section{Algumas ferramentas}

básicas de

administração de

recursos humanos já

não fazem sentido

apesar de estarem

firmemente

incorporadas à filosofia

de gestão

contemporânea $e$ à

expectativa das pessoas

em geral.

\section{A TRANSIÇÃO PARA A ORGANIZAÇÃO DO FUTURO}

As empresas que fazem a transição para formas organizacionais baseadas em processos devem não apenas ir mudando sua práticas de gestão, como também redefinindo a sua cultura e as obrigações mútuas entre elas e seus empregados. Essas empresas esperam que seus empregados apresentem iniciativa em vez de pura aceitação e que demonstrem compromisso em lugar de simples lealdade. ${ }^{41}$ Foi o que

$R A E$ ・ v. 37 - n. 3 - Jul./Set. 1997 ocorreu quando a GTE americana fez a transição para uma forma organizacional centrada em processos.

A GE Fanuc, uma empresa americana especializada em produtos para automação industrial, conquistou seu sucesso nos negócios com base em empregados entusiasmados. $\mathrm{Re}$ centemente, o Departamento do Trabalho americano escolheu a GE Fanuc como uma das dez melhores companhias para se trabalhar. A empresa conseguiu esses resultados reorganizado-se por processos e projetos, organizando seu pessoal em times de trabalho e dando a eles autonomia sem precedentes. Os níveis administrativos foram reduzidos em $70 \%$ e a empresa ocupa posição de liderança no seu setor de atuação.

As empresas estão passando a adotar programas de gestão de recursos humanos baseados na estratégia de oferecer menos garantias aos empregados, mas dando a eles a oportunidade de avançar mais na carreira pessoal e de ganhar mais. É o caso da Owens Corning, empresa industrial americana que também atua no Brasil.

A transformação dos empregados da linha de frente em profissionais de processo implica em ajudar os empregados a entender os desafios, a economia e a estratégia da empresa. Também exige que os empregados entendam os processos fundamentais da empresa e localizem-se nesses processos, em termos de localização e contribuição para o resultado. Para terem sucesso em suas novas ocupações, os empregados precisarão de novos conhecimentos, novas habilidades e novos comportamentos, compreendendo processos inteiros e exibindo iniciativa.

As nossas empresas estão vivendo o desafio de redefinir os seus mecanismos de funcionamento, sem necessariamente incorrer em situações traumáticas, e de viabilizar toda uma nova ética do trabalho vencendo as barreiras da desconfiança e da perda da lealdade. ${ }^{42}$ Elas estão tendo que redefinir seu negócio e se reconstruir sem interromper sua jornada em direção ao sucesso. Todos esses grandes desafios dependem essencialmente da capacitação e do envolvimento do seu pessoal. É indispensável reequipar a empresa com novas ferramentas para lidar com suas pessoas. Neste momento, conhecer o caminho não é suficiente: é necessário ir por ele com determinação.
40. GONÇALVES, José Ernesto Lima. Um novo 0\&M para recuperar o tempo perdido. RAE Light. São Paulo: Fundaçāo Getúlio Vargas, v. 2, n. 3, maio/jun. 1995.

41. HAMMER, Michael. Transforming the workforce (folheto). Boston, Hammer \& Co., 1996.

42. Reestruturação atinge cargos executivos, The Economist, traduzido por Gazeta Mercantll, 16 de abril de 1993 